didan Kesfigian is a PhD studen in the Deparment of Philosophy at Carnegie Mellom University: Her research and teaching interests include denocrutic theon: research ethics, and voting theory: E-mail: akestigian@cmu.colu

\section{Reasoning, Science, and The Ghost Hunt}

\author{
W. JOHN KOOLAGE \\ Eastern Michigan University \\ TIMOTHY HANSEL \\ Edlgewood College
}

\begin{abstract}
This paper details how ghost hunting, as a set of learning activitics. can be used to enhance critical thinking and philosophy of science classes. We describe in some detail our own work with ghost hunting, and reflect on both intended and unintended consequences of this pedagogical choice. This choice was partly motivated by students lack of familiarily with science and philosophic questions about it. We offer reflections on our three different implementations of the ghost hunting activities. In addition. we discuss the practical nuances of implementing these activities, as well the relation of ghost hunting to our course content, including informal fallacies and some models for scientific inference. We conclude that employing ghost hunting along-side traditional activities and content of critical thinking and philosophy of science offers a number of henefits. including being fun, increasing student altendance, enhancing student learning, and providing a platform for campus wide dialogues about philosophy.
\end{abstract}

\section{Introduction}

In pursuit of deep learning, it is helpful to ask what students can do, in order to get a better handle on sometimes foreign and abstract ideas. We asked students to go hunting, ghost hunting in this case, to supplement the usual listening, writing, reading, reflecting, and note taking that regularly occurs in philosophy classrooms. Most students laking philosophy classes at our institutions have little contact with science beyond the K-12 level, and, in our experience, many of these students feel quite uncomfortable with scientific concepts beyond the rudiments of scientific inquiry. Additionally, as students engage with the idea of correct thinking, it is helpful to provide concrete and interesting examples. We connect ghost hunting to ideas critical to correct 
reasoning in general, and scientific reasoning in particular. in order to illuminate those ideas and understand the nature of (good) scientific practice and reasoning.

After a number of short, collaborative discussions, we built, independently, a set of learning activities aimed at enhancing student learning regarding some concepts relevant to critical thinking or philosophy of science classes, including evidence, rational belief formation, critical reasoning, and scientific methodology. The ghost hunting activities are logically consistent with traditional accounts of these concepts, even if these traditional accounts often reveal the philosophically problematic nature of most current ghost hunting practices. We implemented various ghost hunting activities, including an experiential one, in the fall of 2015. The primary goal in Hansel's case, was to apply various critical thinking course content, including methods. to something interesting that they had done. The primary goal in Koolage's case was to provide students with an experience in which students would integrate various ways of understanding basic philosophical views on the workings of science to an experience that is standardly considered to be (at hest) pseudoscientific. These experiences also provided a platform for exploring some of the more abstract philosophic discussions of science, without requiring students to have a background in the sciences.

In this paper, we present the various ghost hunting activities we designed for our students. The paper also contains a number of observations regarding these activities in terms of some surprising successes and failures. As such, it is primarily a process paper, with observations about our own learning activities; we do not have assessment data to share or to support evaluative claims beyond our experience of the utility of the activities. In fact, and perhaps not surprisingly, our experience indicates it would be good to develop a clearer and more precise sel of learning outcomes and redesign future hunting activities in line with our rellections and said assessment. More specifically, in this paper we detail how we connected a ghost hunting activity, treated as a set of learning activities, to philosophy in two distinct areas (critical thinking and philosophy of science) using three distinct approaches: (1) as an extracurricular activity connected to an existing course, (2) as a stand-alone course with ghost hunting as the primary focus, and (3) as a unit within a course.

The material in this paper is divided into three sections. The lirst section explores some of the most compelling reasons for incorporating ghost hunting into philosophy courses. The second section is devoted to exploring ghost hunting at Edgewood College, where it was incorporated as an extracurricular activity for an already existing course; it describes how ghost hunting was used to connect in-class material with investigations outside of class. This includes a practical discussion of planning and implementing such learning activities, as well as an in-depth look at how different pieces of traditional critical thinking course content can be connected to various aspects of ghost Eastern Michigan University, devoted to exploring ghost hunting at and as a unit within as stand-alone course the practical nuthe al science course. It also describes the practical nuances of implementing ghost hunting activities and details how content from a philosophy of science course can be con-
nected to ghost hunting.

\section{Why Use Ghost Hunting in a Philosophy Class?}

There are number of reasons to be excited about the prospect of incorporating ghost hunting into one's philosophy classes. The first, and most important, is that ghost hunting connects to the material we teach in a variety of different ways. We devote the majority of this paper to of science and, at a more deep and difficult topics in the philosophy thinting and at a more intermediate level, to the practice of eritical in taver of using shost we will briefly discuss two additional reasons in lavor of using ghost hunting in the classroom.

\section{Ghost Hunting is Fun}

Ghost hunting is interesting to many of our students. Glosts and ghost hunting pervade popular culture, and belief in the supernatural is relatively high in the United States. According to a 2009 Pew Research 29 percent helit of American adults claim to have seen a ghost, while Furthermore Furthermore, the proliferation of ghost hunting in television shows other areas of populart Adventures, etc.), litms (Ghostbusters), and believe in of popular culture is such that even if a student does not aware of the phenomenon.

Additionally, taking students on ghost-hunting investigations can be the dark in an envion educational. A typical investigation is done in with a spooky environment that, while probably not haunted, is imbued to walling interes of adventure altached lights off and an empty church sanctuary, in late October, with the lights off, and in the middle of the night. It is not often that one finds able to give our investigation and adventure linked. It is rewarding to be able to give our students an interesting and enjoyable experience, alongside our challenging and often highly abstract philosophical material. 


\section{Ghost Hunting Gets Us Out of the Classroom}

Having a unit on ghost hunting provided philosophy (or, at least, a philosophy department) with some good press on campus. As ghost hunting is exciting and a bit weird, word of mouth has spread excitement among the undergraduate population. After one semester of incorporating ghost hunting into his critical thinking class, about half of Hansel's incoming critical thinking students were already aware of the ghost-hunting section and investigations.

Students are not the only individuals taking note. The ghost hunting investigations at Edgewood College have been met with appreciation and (some) excitement from other departments. Notably, it is the science departments that have shown the most interest, especially after Tim explained that he was using ghost hunting as an example of bad reasoning and pseudoscience.

This connection to other departments presents an opportunity to introduce philosophy to those who may not be familiar with what we teach or study. This also affords us a valuable opportunity to clear up possible misconceptions about the material as well. The critical thinking, epistemology, and philosophy of science material that we teach our students is often compatible with what is being taught by the sciences. This sometimes comes as a surprise to our colleagues from the sciences, as some assume that philosophical and scientific methodologies are at odds. These investigations demonstrate that, in many ways, science and philosophy are compatible. With these considerations in mind, we decided to incorporate ghost hunting into our teaching at Edgewood college (Tim Hansel) and Eastern Michigan University (John Koolage).

\section{Ghost Hunting at Edgewood College}

At Edgewood, all students are required (usually during their first or second semester) to take a critical thinking course. I decided that the best way to incorporate ghost hunting into my teaching would be to augment the sections of critical thinking that I already teach. I had two goals in mind as I went forward: First, I wanted to afford students an opportunity to apply critical thinking material to real-world scenarios (ghost hunting is a thing that happens, even if there are no ghosts). ${ }^{2}$ Second, I wanted to introduce students to the more in-depth philosophy of science material in a manner that was accessible to predominantly first-year students. So, I augmented my critical thinking course by focusing (a bit) on ghosts and the supernatural inside the classroom, and I set up an extracurricular ghost hunting group to meet, discuss, and investigate. Below, I describe these elements in some detail.

\section{Connecting Ghost Hunting to a Pre-Existing Course}

My use of ghost hunting in the classroom began in the Fall Semester of 2015. I made no changes to the basic structure of the course itself. As critical thinking is about the evaluation of belief (both ordinary and extraordinary), the material regarding how to think critically about beliefs remained basically the same. What was different for my class, was the focus on supernatural beliefs and evidence we may (or may not) have for them. For example, when we discussed the reliability (and unreliability) of personal experience, I would focus on purported first-hand supernatural experiences. If we were discussing explanations, we would look at ghostly and other supernatural explanations and ask whether we had any reason to believe them over more mundane explanations.

Much of what we did regarding paranormal beliefs and ghost hunting occurred outside of class. This was deliberate. As I was not substantially revising my standard critical thinking course, it would be inappropriate to do too much in the classroom beyond applying the standard material, from time to time, to the guestion of the supernatural. Furthermore, students had no reason to expect a class with such a focus, and the topic can make sonne students uncomfortable. ${ }^{3}$ Finally, as the critical thinking course is meant to be introductory, I wanted to make the more high-level philosophy of science material optional. Also, our activities outside of class were often used as examples and discussion topics inside of class. Additionally, I occasionally shared anecdotes and pieces of evidence from our investigations and online discussions with the class when relevant.

As this was all extracurricular, I needed to consider the time commitment that such a project would require. My goal was to offer four to five meetings, investigations, and other events per semester. The events typically last about two hours, so 1 planned for approximately ten hours of work outside of the class with students, along with another ten hours for the planning and organization of these events. Obviously, more or less time could be devoted to such a project if one wanted to offer a different number of events.

In order to gauge student interest in the topic, I first set up a Facebook group devoted to ghost hunting at Edgewood. We named the group the Edgewood Center for Thaumaturgic Observation (ECTO). About half of my twenty critical thinking students signed up for the group, along with others who had heard about the group. We ended up with nineteen student members in the group in the first semester. On the group page, I posted the more in-depth philosophy of science readings for later discussion. ${ }^{4}$ We also used the page to plan investigations and discuss any evidence from those investigations (and elsewhere). 


\section{Investigations}

In the fall of 2015, we performed two investigations in the manner of those performed on television programs like Ghost Adventures. ${ }^{5}$ The first was on campus during daylight hours. We met in a wooded area on campus to investigate rumors that the campus's effigy mounds were haunted. Eleven (out of a possible twenty) students came to this investigation. As it was our first go at such a thing, we spent most of our time familiarizing ourselves with the typical ghost-hunting gear (cameras, voice-recorders, EM field detectors, and $\ln$ frared thermometers).

The second investigation took place at an older church chapel (also rumored to be haunted) within walking distance of campus. The church gave us permission to stay the entire night on the premises and gave us complete access to the sanctuary and fellowship areas. During this investigation, we did experience some initially very spooky phenomena that required explanation. The most interesting was an image captured by one of the cameras that appeared to show a figure in the choir loft. The students decided that it was not supernatural. In fact, they concluded that it was merely reflected light from the flash of the camera.

One key element to the success of these investigations as a learning activity was facilitating discussions regarding the connection of the hunts to relevant readings and class topics. Before and after the investigations, we would have conversations about what we had been reading regarding the nature of scientific investigation, and whether what we were doing would constitute legitimate scientific inquiry (see Koolage's two questions in his section, "Ghost Hunting at Eastern Michigan University," below). We would also examine any data that had been collected or submitted. Through our conversations, we noted that one of the biggest challenges facing ghost hunting was how to come up with a testable hypothesis. Students were interested in the notions of falsitiability and testability (see the next section), but had difficulty coming up with hypotheses that had any predictive content that could be tested during our investigations. The other major theme of our discussions related to spooky phenomena caught on tape and camera. Conversations inevitably lead to questions about competing hypotheses. We had numerous discussions focused on inference to the best explanation and likelihoods (see below for more detail) to try to sort out what explanations (hypotheses) were most likely to be true.

Other discussion and meetings occurred that were not directly related to ghost hunting, but continued the theme of the supernatural. In the fall of 2016, the ECTO group held an on campus event where students and faculty were encouraged to share their own ghost stories. We then discussed the reliability of such testimony and whether such stories could ever provide sufficient justification for supernatural beliefs. In the appeal to authority/testimony section below, we provide more detail on the issue of the reliability of ghost stories and supernatural reports.

\section{Connecting Ghost Hunting to Critical Thinking Content}

At Edgewood, part of the purpose of having the extracurricular ghost hunting events outside of class was to allow students to find greater depth within the philosophy of science. However, much of what happened (inside and outside of the classroom) connected to the basic methodological elements that one finds in a standard critical thinking course. At this level, greater focus is given to understanding concepts and less to genuine philosophical debates. For instance, although critical thinking textbooks almost universally cover inductive reasoning, very few mention the problem of induction. For my class, we use Lewis Vaughn's, The Power of Critical Thinking." In this section, we will briefly discuss how various elements of a standard critical thinking course fit with ghost hunting. In the next section, we will discuss in much greater detail how the plienomena fits with various topics in the philosophy of science.

\section{Inference to the Best Explanation}

In Tim Hansel's critical thinking courses, a third of the semester focuses on inductive reasoning with an emphasis on inference to the best of glanation (IBE), scientific methodology, and epistemology. ${ }^{7}$ The use of ghosts and ghost hunting (in and out of class) allows us to apply all of the techniques for evaluating inductive inferences regarding sup-
posed supernatural phenomena.

Inference to the best explanation is the inductive inference that has the most relevant connection to ghost hunting. ${ }^{8}$ Here is the inference to the best explanation argument as found in Vaughn's The Power of
Critical Thinking:

I. Phenomenon Q.

2. E provides the best explanation for $\mathrm{Q}$.

3. Therefore, it is probable that $E$ is true

In teaching IBE, most of the work comes from trying to unpack what it means for one explanation to be better than another. At an introductory level, this comes down to which explanation best embodies certain explanatory virtues. These virtues typically include simplicity, conservatism, consistency, testability, and the like.

When ghost hunting and during discussions in and outside of class, we consider competing explanations for the various ghostly phenomena that we have experienced throughout the semester. Some of it occurs during investigations, and some of it comes from other sources. We then, through discussion and writing assignments, try 10 apply our 
evaluative tools to making an inference to the best explanation (if possible).

Here's an example: during the Spring 2016 semester, a student posted pictures of an 'orb' on the ECTO Facebook page. After securing the student's permission to discuss the evidence in class, I used these photographs to talk about the best explanation for the reddish ball that was visible in a photograph of some artwork in the lounge of one of the on-campus residence halls. The student claimed that it was a visual manifestation of a spirit. Furthermore, according to the student, the redness of the orb indicated that it was a "protector" spirit.

During this discussion, we noted that several more mundane explanations (reflected light, camera glitch, dust on lens) did just as well, if not better than the supernatural one from the standpoint of the explanatory virtues. For instance, the mundane examples were all superior to the supernatural explanation in that they were more conservative and simple. They were conservative in that they described phenomena that fit well with what is already well-established (e.g., we know how light reflections interact with camera lenses). Furthermore, mundane examples are simpler, as they do not need to posit extrat ontological baggage to explain what we observe. Though as a group we were unable to settle on one "best" explanation, we were all relatively sure that the supernatural explanation was unlikely to be true, given the adequacy of competing mundane explanations.

\section{Fallacies}

Most critical thinking courses include some discussion of informal and formal fallacies. In the critical thinking courses at Edgewood, when I discuss informal fallacies, I often note their appearance in arguments and beliefs about ghosts and other supernatural phenomena. Below are five common fallacies as they relate to supernatural beliefs. This list is not exhaustive, it merely provides some examples of how the conversations look when connected to the material.

One fallacy that is often committed when reasoning about supernatural entities and phenomena is the appeal to ignorance fallacy. This fallacy occurs when someone mistakes the lack of negative evidence for positive evidence. In class, I had a student who believed in ghosts tell me, referring to some supposed piece of evidence of the supernatural, to prove that it wasn't caused by a ghost. Such a classic appeal to the ignorance fallacy afforded a great teachable moment.

A second fallacy that often comes up in discussions of ghost hunting is the appeal to authority or testimony. Are the people on Ghost Adventures (or any of the other TV shows) experts? How about the author of The Everything Ghost Huming Book?" What should we say about anyone who has claimed to have seen a ghost? The appeal to authority fallacy occurs when someone imparts an unreasonable amount of credibility to the testimony of individuals. Whether ghost hunters' (or others') testimony is reliable is an extremely fruitful conversation.

When discussing testimony in a critical thinking course, we go into some detail about whether we have reason to believe that the testifier is in a position to know the information they are claiming, and whether the testifier is being sincere. With accounts of supernatural events, these issues can come into stark relief. When we hear a ghost story from a ghost hunter, student, or any other source, we immediately ask several questions. Did the testifier truly see what she said she saw? For example, was it a human ligure in the doorway or the mind playing tricks? Does she have any reason to fabricate or embellish her account? Even if there were no mistakes or embellishments, does that mean a more mundane explanation is ruled out? Given the shortcomings of testimonial accounts of supernatural phenomena, we can emphasize the need for more direct (and adequate) evidence for the supernatural.

Formal fallacies make an appearance as well. A third common fallacy is that of a false dilemma or false choice, which occurs when we present a number options as though they exhaust the possibilities when, in fact, they do not. Again, this kind of thinking occurs often when discussing the supernatural. Here is the thinking: we have ruled out one possible mundane explanation; therefore, ghosts! Clearly, this is fallacious reasoning.

A fourth, is an appeal to emotion or wishful thinking. All critical thinking courses warn against emotion. That is to say, that our emotions can, at times, interfere with our ability to think rationally. One of my favorite examples of this fallacy is wishful thinking. I tell my students that I want ghosts to be real. Growing up in the 1980 's, all I wanted in the world was to be a ghostbuster (I still kind of do), but wanting something to be true is irrelevant to something being true. We must be careful that we do not believe things simply because it makes the world a more interesting place.

The fifth fallacy that easily connects to supernatural belief is cognitive biases. Cognitive biases are those psychological impediments that can sometimes misrepresent the world and evidence to us. Being aware of these biases, like being aware of errors in reasoning, will (hopefully) allow us to minimize error. One of the more interesting of the biases to cover in a critical thinking class is pareidolia. Pareidolia occurs when we experience patterns and structure from random stimulation. Purported evidence for ghosts and the supernatural are considered classic examples of pareidolia. Secing faces in the grain of a photograph or hearing voices in the noise of a recording (known as Electronic Voice Phenomenon or EVP) may just be our mind playing this very specific kind of trick on us. 


\section{Ghost Hunting at Eastern Michigan University}

Ghost Hunting as a Stand Alone Course

In Winter 2015, our Introduction to University course added a one credit hour lab, taught by faculty. I proposed a lab that focused on the question 'what is science?' From a discussion of this proposal, the idea of a focus on the demarcation of science and pseudoscience emerged. I had previously taught sections of Philosophy of Science and The Occult as part of a philosophy of science course, and when ghost hunting appeared to be exciting to the Introduction to University design group, I began preparing the lab. ${ }^{10}$ When I met with Tim in the summer of 2015. our collective interest in thinking about ghost hunting in terms of philosophy of science and critical thinking sealed the deal. The ghost hunting lab for Introduction to University occurred in our Fall 2015 semester, and was compleled in eight class sessions, or roughly twelve hours of class time.

\section{Ghost Hunting as a Unit within a Class}

The third model, where ghost hunting is used as a unit in a course. was instantiated in Winter 2016 in my Philosophy of Science class (a $400 / 500$ level course). A.typical issue that emerges in philosophy of science classes is that students are surprisingly unfamiliar with the sciences and scientific practice." I opted to scale down my Introduction to University ghost hunting unit as a response to this challenge. The unit took 4 weeks of class time, and was also connected to a unit on scientific realism.

The two models differed in a number of ways, especially in terms of their student populations and the teaching and learning needs of students at very different levels. I will focus here on the commonalities, especially the experiential component. Both models included a ghost hunting experience, which will be described below. In both models, students were divided into groups of three to five. Both models also required students to give group presentations, wherein they reported on their methods and findings. In particular, students were asked to offer their own connection between the experiential component, the scientific inference patterns deployed, and whether ghost hunting is a science. Additionally, the groups were given a worksheet intended to facilitate making useful connections between ghost hunting (as prac(iced) and course content. ${ }^{12}$

The ghost hunts required about two hours of additional preparation. At the lime, Starkweather was the home of the Honors College and General Education. I contacted both groups to be sure that my ghost hunters traipsing through wouldn't be a problem. In the second itera- tion, both groups had moved out of Starkweather, so I had a number of discussions with our physical plant regarding the use of, and access to, the building. Students were encouraged to get ghost hunting gadgetry, which (interestingly) is available at the local public libraries.

\section{Investigations}

For the experiential component of the unit, students were asked to proceed with a scientific inquiry into the possible haunting of Eastern's Starkweather Hall. The Hall is rumored to be haunted by Mary Starkweather's ghost, and plenty of material regarding this haunting is available on the web. ${ }^{13} \mathrm{I}$ secured access to Starkweather Hall during our regular class time. After all, what scientist would operate under sub-optimal epistemic conditions, like darkness? Students were encouraged to get ghost hunting equipment, available at the Ann Arbor public libraries, and were required to read The Evervthing Glsost Mumting Book in preparation. ${ }^{14}$ Only two groups brought technical gear, but most students brought some sort of detection and recording devices (phones, cameras, and in one case an old school tape recorder). Honeslly, the students took this endeavor pretty seriously, and it was fun to watch them proceed in a manner they thought a ghost hunter should.

\section{Connecting Ghost Hunting to Philosophy of Science Content}

There is a host of traditional philosophy of science content that can be connected to ghost hunting, but my classes focused on questions of scientific epistemology-the patterns of inference involved in justifying (understood broadly) scientific claims (hypotheses). The pair of organizing questions I used for my courses are as follows: (1) if a ghost hunter were a scientist, how would she proceed? And, (2) how does this scientist ghost hunter match actual ghost hunter practice?

In order to answer the lïst question, my class focused on these questions: what are some proposed hallmark forms of scientific reasoning, how well can we translate these to dealing with ghost hunting, and what do these translations reveal about our understanding (or lack thereof) of the hallmark forms of reasoning? In order to answer the second question, we read about and went ghost hunting.

Overall, the experiential component of my ghost hunting activities was well received by students. Many of them took the hunt very seriously, and had a good deal of fun weaving through the creepy basement of Starkweather. Every group did the legwork to understand the nature of the possible haunting of Starkweather. All the groups did an excellent job of using the handout associated with the ghost hunt. The students also bonded, which certainly made discussions and group work after the ghost hunt itself notably more casual and trusting. It was a lot of 
fun to see them making use of various ghost hunting paraphernalia and some entertaining preconceptions about ghost hunting. Additionally, the ghost hunting class sessions had 100 percent attendance, which is not the case for the more typical lecture/discussion sessions.

The greatest failure of this experiment is that I did not directly connect the key (content based) learning outcomes to the activity for the students. I had assumed that they would come to this on their own, but it did not really happen. I had expected that students would use the various tools at their disposal (the models of scientific inference offered below) to discover the main problem for ghost hunting: the standard observations associated with the presence of ghosts are not linked to hypotheses about ghosts in a way that would be considered scientific by any of the philosophers of science we discussed in the lecture/discussion elements of the course. I presented them with a number of accounts regarding the connection between observations and hypotheses, and the nature of hypotheses, and I was really hoping that students would make this connection on their own. In retrospect, that was a missed opportunity. Students would have moved more deeply and more quickly into the material if this outcome had been made explicit. When I do this again, I will simply tell students that a central philosophic puzzle here is to find a relation between the models of scientific reasoning and the process of ghost hunting (and, if one can't be found so much the worse for one or the other). That is, ghost hunting can only be a science if its primary reasoning palterns are scientific, or, conversely, we can learn about the nature of scientific inference where standard models fail to capture ghost hunting. Of course, most student realized that they were to critique ghost hunting as a science using the inference patterns (models) presented, but it is clear from my teaching experience that the connection of the hunt and the models of science would have been more useful to the overall course if this connection were made for them. In short, greater transparent alignment is required in this area.

\section{Are Ghosts the Kind of Thing that Is Excluded from Scientific}

\section{Evaluation a priori?}

It is very common to think that science requires Naturalism, or even Physicalism. I am extremely skeptical that science requires either of these. It is also very common to think that science is identified by the objects studied, namely natural objects. Since it could easily be argued that ghosts conform to none of these three common views of science, ghost hunting is a priori out of bounds as scientific investigation, and in turn not possibly a science. While this section appears first, I taught this section last; students, unlike professional philosophers, are not particularly concerned that ghosts might be outside of scientific boundaries, especially if they are learning about ghosts and philosophy of science in a classroom. Additionally, the readings for discussion are high level and use some of the language and ideas presented in the reasoning pattern sections.

\section{Naturalism}

The concept I have in mind here is the one that suggests that science must eliminate or avoid supernatural objects in its theories. If this is correct, then it is extremely difficult to see how ghost hunting could be a science. Naturalism (of this sort) does appear to be a part of the recent history and practice of science, but a priori rules placed on admission to the scientific endeavor are notoriously difficult to justify and have a mixed track record.

The three readings I used to generate some discussion on this topic were (1) Elliott Sober's Philosophy of Biology, chapter 2, (2) Sober's "Evolution without Naturalism," and (3) Kristin Andrews"s The Animal Mind, chapter 2.15

Andrews's chapter provides two discussion items relevant to this topic. She considers, in a careful and accessible manner, Morgan's Canon." The Canon has been a central principle in animal ethology for some time, and it suggests we should never explain animal behavior by appeal to higher order cognitive processes (e.g., the manipulation of beliefs) when they can be explained using perceptual systems and processes (c.g., affordances, which are characterized by a harmony between perceptual mechanisms and the world itself). The Canon has been treated as an a priori principle in animal ethology, and Andrews argues that it is not a justified principle. In this discussion, she also considers behaviorism, another tradition with an a priori prohibition on certain kinds of hypotheses. ${ }^{17}$ Both discussions provide ample opportunity to discuss the idea that scientific hypotheses are judged on the basis of evidence, not a priori prohibitions. Andrews's chapter also provides an appeal to a certain level of expertise in framing observations about unfamiliar phenomena. She suggests that avoiding epistemic errors, such as anthropomorphizing animal behavior, do not require a priori prohibitions, they simply require a level of familiarity and careful observation of the phenomena in question. In my experience, this conversation does not have any particular end game in terms of ghost hunting, but it opens students' eyes to the role of philosophers in thinking about good scientific reasoning.

Elliott Sober's article, "Evolution without Naturalism," is more straightforwardly relevant to the discussion. ${ }^{18}$ In this article, Sober provides some tools for talking about various kinds of Naturalism, but more importantly he demonstrates why particular religious beliefs, 
such as the existence of God, are simply not at odds with the evidence (and justification) for evolutionary theory. Sober deploys the Bayesian framework and the likelihood theory of evidence to show that the existence or non-existence of God is simply not at issue in the testing of evolutionary theory. Additionally, he provides a nice discussion about the role of mathematical objects in science, and further claims that numbers are similarly not being tested when evolutionary models are being tested. The relevance to the ghost hunting questions is that Naturalism is not a requirement of, nor is it a justified principle for doing. good science.

Chapter 2 of Sober's Philosoplyy of Biology, which by now I would have taught in an earlier section of the class, marks an important return to earlier learning. ${ }^{19}$ In this section, I focus on how he is not ruling out Creationism with some principle; he is arguing that Creationism is either (a) a failed science, (b) not proceeding in a scientific manner (generating testable auxiliaries), or (c) at best a degenerative research program (no new hypotheses or predictions).

In all, the suggestion that Naturalism provides us with a reason to dismiss ghost hunting a priori is not a promising line of reasoning, and seems to miss some important features of scientific inquiry. This section also provides a nice avenue for talking with students about some of the limits of scientilic inquiry and placing science nicely in a community of knowledge disciplines, rather than leaving science as a monolith of human inquiry. ${ }^{21}$

\section{Physicalism}

Many philosophers find physicalism extremely plausible, and many people take physicalism or an assumption of physicalism to put ghost hunting out of the running as a science. This view can be (roughly) summarized as follows: all that really exists are the objects described by a correct physics. Most students do not ascribe to this view, but it is worth mentioning in the discussion of Ghost Hunting.

Antony Flew's essay "Parapsychology: Science or Pseudoscience?" argues that most parapsychology, which, broadly construed, would include ghost hunting, rests on an outmoded Cartesian assumption of Dualism. ${ }^{21}$ While I did not address this in my offerings of the ghost hunting unit, I imagine many would find this an interesting and helpful discussion. If physicalism (or some sort of eliminative materialism) is correct, then it is impossible that ghost hunters are hunting anything that would resemble a commonsense notion of ghosts.

An obvious response to this worry is that biologists do not investigate particles, forces, and the void, and yet biology is clearly a science. There are two problems with this line of defense for ghost hunting, though: (1) biology may supervene on the physical, and (2) biology is at, the very least, not logically incompatible with physicalism. There is much to say here, but for students being introduced to the philosophy of science, I took three lines on this discussion. First, the idea that physicalism places a constraint on what counts as science has all the same flavor of the a priori rule found in the discussion of Naturalism. Second, I did not address the notion of supervenience. Additionally, the question of supervening is largely a metaphysical point, rather than an epistemic one. That said, this issue can be addressed (roughly) in a discussion of this question: do all sciences, ultimately, need to be reducible to physics? I directed students to an idea I have been calling 'Theoretic Actualism.' The idea here is that we are only able to believe theories we do have, since it is ridiculous to ask current knowers to believe theories they have never heard (or may never hear). Currently, there is no reduction between concepts found in sciences, such as biology, to concepts in physics. For example, we cannot translate the study of predation to the study of Schrodinger's equation; so, for now, we ought to accept that the two sciences, biology and physics in this case, offer us predictively successful (and possibly truth tracking) accounts of the world, and that the relation between the two sciences is largely unknown. Third, biology and physics are compatible in their current form because they (mostly) do not have overlapping domains. This is not so for ghost hunting and physics. It seems that ghost hunting (at least) requires us to accept that there are other things than what physics names as the most fundamental elements of our world. If there are spirit things that have impacts on physical things, we have a puzzle. Does physics tell us about the world at the rock bottom, or do we need other "sciences" to tell us about that? Again there is much to say on this matter, but I focused the discussion on this set of points: (1) Physicalism seems to ask us to admit that physics trumps other potential or actual sciences; so, if two theories are incompatible, physics (or those compatible with physics) always wins. (2) It is actually not obvious (for reasons we will discuss in subsequent sections) that ghost hunting is incompatible wilh physics. An example I have found useful in this discussion is Alfred Wegener's theory of continental drift. Wegener was the first to offer a sustained defense of the movement of the Earth's crust, but he faced serious opposition from the physicists of his time. ${ }^{22}$ The physicists argued that there could be no Earthly force strong enough to move the block of earth making up England through the block of earth making up the seafloor in the opposite direction of Greenland. Given the sciences of the time, the physicists seemed completely in the right, though Wegener's data suggested the physicists had to be wrong. Should data or theory setlle this question? History demonstrates that Wegener's ideas were pursued, despite the conllict 
with physics, and eventually became mainstream science, though in the form of a newer theory, plate tectonics.

\section{The Objects of Science}

Obviously "ghost" is not a theoretical term in any standard science. We have terms such as orbit, force, virtual particle, cognition, posttraumatic stress disorder, ecosystem, adaptation, planet, and so on, but the some are inclined to think that the sciences are determined by what the science studies-its objects. If that is so, then ghosts are not the kind of thing about which there is a science. This line of thought can be displayed by tracking the Facebook meme "I fucking love science,' wherein cool natural objects (critters, events, and places) are celebrated under the name 'science.'

find a discussion of Larry Laudan's Pessimistic Mela-Induction helpful in a number of ways, so most of my students hear about this sel of ideas at one point or another. ${ }^{23}$ In both models of my teaching of ghost hunting, I had already taught this, but I will describe it here, as it addresses the exclusion of ghosts from science on the grounds that they are not current theoretical posits of any science.

Science cannot be defined (in any sense) by the objects it investigates. In Laudan's article, "A Confutation of Convergent Realism," he lays out a number of examples that nicely demonstrate that the objects of science change, often quite dramatically, over time. ${ }^{24}$ I often pick an example or two depending on the interests of the class, but some examples include electromagnetic ether, phlogiston, Aristolle's elements, élan vital, the Hippocratic humors, and so on. Of course, it is equally interesting to demonstrate that new objects are also being added to the scientific corpus on a regular basis, for example gravitons, mirror neurons/systems, and nomad planets. This discussion is typically fairly quick; however, it introduces students to the idea that sciences to not produce a set of fixed facts, and directs them to a much more important idea-science is more likely to be identified ("defined") by its methods, not the set of objects it currently investigates using its current set of concepts.

\section{Abduction}

The term 'abduction' is ambiguous. In this section of my ghost hunting unit, I lalk about abduction in terms of hypotheses, rather than explanations or probabilistic inference. Henry Frankfurt's article, "Peirce's Nolion of Abduction," provides a basis for discussion. ${ }^{25}$ Frankfurt argues that Peirce's account of abduction provides two, mutually incompatible, conceptualizations. On the one hand, his view is that abduction fundamentally involves some sort of flash of insight-a creative process that admits of no particular rules and invokes an imaginative process.
On the other hand, Peirce conceives abduction as a specific sort of inference pattern. On this way of thinking, Pierce provides us with an inference of the following form:

1. The surprising fact $C$ is observed.

2. If $A$ were true, $C$ would be a matter of course.

3. Hence, there is reason to suspect that $A$ is true.

Frankfurt emphasizes this point: an inference admits of rules and includes all of the concepts required to evaluate it. As a result, this way of thinking about abduction is, thus, doubly at odds with the Mash of insight account. Frankfurt concludes that this second way of thinking about abduction is most useful and faces the fewest problematic challenges. Furthermore, he takes the proper analysis of this conception of abduction to be as follows: abduction is the logic by which we recognize a proposition to be a hypothesis. Put another way, it provides a baseline for scientific reasoning. If science is "defined" by the testing of hypotheses. we must have a way of recognizing what constitutes a hypothesis. On Frankfurt's analysis the inference reads as follows:

1. The surprising fact $C$ is observed.

2. If $\mathrm{A}$ were true, $\mathrm{C}$ would be a matter of course.

3. Hence, we recognize that $A$ is a hypothesis about $C$.

I have found it useful to point out that abduction is a fairly weak inference; as a result, it cannot be the only sort of scientific inference. A successful abduction gives us no more reason to believe its conclusion than some competitor that also makes an observation a matter of course. Using historical examples, it is easy to demonstrate these issues. Consider any of the ancient Greek explanations for natural phenomena, which would make various observations a matter of course. This also opens the opportunity for a discussion of what 'a matter of course' might designate. Does it analyze as a form of least surprise? Or something more complicated, such as predictive success?

As far as the discussion of ghost hunting is concerned, I have found that abduction, in this second conceptualization, is absolutely critical. If the ideal ghost hunter were a scientist, how would she proceed? She would most assuredly want to formulate hypotheses that make standard ghostly phenomena a matter of course if there are ghosts. If left to their own devices, students puzzle over how to go about ghost hunting and simply try whatever strikes them as the usual methods or whatever bizarre notions TV shows and the internet offer. This represents a failure to understand the lesson of abduction. To have a science of ghost hunting, one must start with hypotheses. A good hypothesis would tell us how the existence of ghosts makes the appearance of "orbs" in photographs, goosebump inducing sounds, the presence of "chatter" on a tape recorder, or the presence of "ectoplasm" a matter of course! I am 
not skeptical that a clever ghost hunter could resolve such a problem, since the abductive inference is not particularly strong. That said, this is not standard procedure for ghost hunters. To demonstrate this, one can return to what is said about ghost hunting in popular texts, such as The Everything Ghost Huning Book by Melissa Martin Ellis. ${ }^{26}$

Of particular concern in this discussion is what makes something a matter of course. I asked students to generate some potential principles for this idea. Students generated suggestions that came close to the following three ideas: (1) minimization of surprise or meeting of expectations, (2) fit with data, or (3) fruitfulness. Connecting this to the ghost hunting activity is reasonably straightforward. The postulation of ghosts must make some sel of observations (creepy sounds, the appearance of "orbs" in photos, and so on) either (1) expected or unsurprising, (2) highly probable, or (3) useful for the generation of additional questions and further inquiry. The ensuing discussion focused on the nature of these ideas. The first is at least a psychological principle, the second is epistemic (and I return to it below), and the third is pragmatic. My classes focused on the second criterion, since it is central to the discussion of Likelihoodism. To repeat an earlier lesson from niy use of the ghost hunting activity, it would be helpful to have students explore the idea that there must be some sort of connection (preferably epistemic) between the data one has (or will have) and the hypothesis that there are ghosts. In this way, students can begin to see that there are some serious problems with the possibility that currently practiced ghost hunting is a science, while simultaneously addressing the idea that the inferences of science are part of what makes it an important, and philosophically interesting, mode of inquiry.

This discussion also provides a nice introduction to thinking about stronger inference patterns: exactly how are hypotheses and data connected such that the latter epistemically supports the former. The first pass at some principles of connection provides students with some insight into a key puzzle in the philosophy of science.

\section{Falsificationism}

The weakness of abduction leads nicely to a discussion of Popper's Falsificationism. The desire to rule out hypotheses that capture various phenomena (make them a matter of course), but are bizarre or unhelpful, appears obvious after students grasp the basics of abduction. The fact that Hades's anger would make volcanic eruptions a matter of course is usually sufficient to convince students of the need for a stronger inference in (most) scientific inquiry.

Popper's piece, "Science: Conjectures and Refutation," serves as a good way 10 introduce the standard reading of Popper's Falsificationism. ${ }^{27}$ This piece also provides an opportunity to look at some views that remain popular, including Marxism and Freudianism; Popper critiques these as unscientific on the grounds that they do not have falsifiable content.

Popper's falsification follows a familiar formal, Modus Tollens:

I. If $\mathrm{H}$ (hypothesis) is true, then $\mathrm{O}$ (observation) is true.

2. $\mathrm{O}$ is false.

3. Therefore, $H$ is false.

Hypotheses are linked to a set of observations. This set is sometimes known as the hypothesis's empirical consequence class. Popper captures Peirce's notion of making the observation 'a matter of course' with material implication. That is, if the hypothesis is true, then we will observe elements of the hypothesis's empirical consequence class. In this way, hypotheses are falsifiable. If we observe the negation of elements of the hypothesis's empirical consequence class, then the hypothesis is false. If there are no empirical consequences that could render the hypothesis false, it is unfalsifiable and not scientific according to Popper.

It is easy enough to demonstrate why sciences are engaged in falsilication, rather than proof, when material implication does the work. Consider the 'proof' argument:

1. If $\mathrm{H}$ is true, then $\mathrm{O}$ is true.

2. $\mathrm{O}$ is true.

3. Therefore, $\mathrm{H}$ is true.

This is an instance of affirming the consequent-a logical fallacy.

In my class, I introduce two problems for Falsificationism. First, corroboration (what happens when we do an experiment and we don't get the result that $\mathrm{O}$ is false) does not capture our intuitions about good hypotheses. Corroboration never tells us if the hypothesis is true, or even approximately true; it merely tells us that the hypothesis is not false. This result clashes with our intuition that a highly corroborated hypothesis is much better than one that has only been put to task a few times. This 'much better' notion cannot be measured in terms of truth. So, we are left with a puzzle-can this normative term ('much better') be cashed out in meaningful epistemic terms (that do not have to do with (ruth), and if not, what does it mean to engage in scientific inquiry? I have left this as a puzzle for students to explore, though, so far, none have taken it up in final papers. Second, I introduce QuineDuhem underdetermination as a problem for Popper's Falsificationism, which is delailed below.

Clever students often notice that material implication is not particularly impressive as a means of linking observations and hypotheses. Consider the ghost hunting example. If there are ghosts, then humans will observe spooky sounds in spooky places. Is this material implica- 
tion true? How would we know? The connection between hypothesis and observation needs more detail. In traditional sciences, we can sometimes deduce the implication from a theory. Consider something simple, such the distance an object will travel in a fixed period of time. In classical mechanics this sort of problem is resolved using one of Newton's motion equations: e.g., $d=v t+1 / 2 a^{2}$. With this equation, derived from the definition of acceleration in Newton's theory, we can generate falsifiable hypotheses. If Newton's motion equation (H) is true, then we will observe, for example, that an object that begins at rest and is accelerated at one meter per minute for one minute will be displaced by half a meter (O). Such deductions are not so obvious in most cases, or even most sciences. To make matters worse, Quine (and Duhem) note that such deductions require auxiliary assumptions. For example, the motion equations require the assumption that acceleration is constant. Worse, to record the initial conditions and resulting displacement accurately, we need the assumption that light travels in a straight line. We need to understand how "seeing" works. And, so on. In order to test a hypothesis on the Falsificationist account, we need a host of auxiliary assumptions (the constancy of acceleration during the experiment, facts about optics. facts about our visual capacities, and so on). This is a serious problem for Falsification.

Consider the form of the argument:

I. If $\left(H \& A 1 \& A 2 \ldots \& A_{n}\right)$ is true, then $O$ is true.

2. $O$ is false.

3. Therefore, at least one inember of the $\operatorname{set}\left(H, \ldots, A_{n}\right\}$ is false.

We cannot falsify $\mathrm{H}$, since it could always be one of the auxiliary assumptions that is false. In this way, a falsifying observation does not determine whether or not $\mathrm{H}$ is false-hence, this problem is known as Quine-Duhem Underdetermination.

For our would-be ghost hunters, three puzzles emerge. First, can we formulate material implications linking hypotheses about ghosts to observations that are sufficiently robust for a properly falsifying, modus tollens? Second, are sciences really required to offer sufficiently detailed theories such that we can deduce hypotheses and linked (by material implication) observations? And, finally, is the inference pattern laid out by Falsificationism really a fruitful account of scientific inference in light of Quine-Duhem Underdetermination?

Most students found the ideas in Popper's work helpful to think about in relation to the ghost hunting experience, but very few pursued these ideas in final papers. The idea that the distinction between science and non-science should be cashed out in terms of testability (falsifiability), and the pervasiveness of the idea that scientists try to show their theories are false, make Popperian Falsification worth grappling with. Additionally, the basics of Popper's view help students understand the idea that the observations that contribute to our belief or disbelief in scientific hypotheses must be linked to said hypotheses by more than "common sense" or idiosyncratic experience. It is safe to say that material implication is probibly not the right link, but it is far betler than what contemporary ghost hunters have to offer.

Another, in hindsight, missed opportunity was to provide a greater discussion of Popper's work on ad hocery. In Popper's later work, he spent some time addressing the idea that the rationale for preserving a hypothesis (and blaming an auxiliary) in light of 'falsifying' observations, or a modification to a hypothesis, was critical to its status as scientific or unscientific. This would be of value in evaluating ghost hunting as it currently occurs, since 'ghost hunters' offer all sorts of ad hoc response to failed hunts, including psychologizing the ghost, failure to properly place equipment, other background 'noise,' and so on. ${ }^{28}$

\section{Likelihoodism}

Thinking of the scientific enterprise as comprised of testing hypotheses by way of observations offers several possibilities, beyond Popper's, for the testing relation. Bayesians suggest that testing consists in updating our confidence in a hypothesis on the basis of its degree of fit with observations. While I do go on to teach Bayesian Epistemology in my philosophy of science classes, a full discussion of such an epistemology is not necessary to make some interesting points about the nature of science and its relation to ghost hunting. In this section, I focus on Likelihoodism, a somewhat narrower epistemology than Bayesianism, and one that will serve to augment some of the more promising concepts from the previous section.

Likelihoods are a way of expressing the fit with data relation that is used to judge many scientific hypotheses. Likelihoods are specific form of conditional probability, and are expressed mathematically as follows: $\operatorname{Pr}(\mathrm{OIH})$. This mathematical expression is read as follows: the probability of an observation, $\mathrm{O}$, given that the hypothesis, $\mathrm{H}$, is true. I will say a bit more about this shortly, but Likelihoods have been used to express the concept of evidence, and this is a key concept for our ghost hunting unit.

lan Hacking's Law of Likelihood provides a way of comparing hypotheses using Likelihoods:

The observation O favors the hypothesis $\mathrm{HI}$ over the hypothesis $\mathrm{H} 2$ if and only if: $\operatorname{Pr}(\mathrm{OIH} 1) \gg \operatorname{Pr}(\mathrm{OlH} 2)^{29}$

The favoring relation described in the Law of Likelihood is often taken to capture the idea that the observation, $\mathrm{O}$, provides evidence for $\mathrm{HI}$ 
relative to $\mathrm{H} 2$. So, on this account, testing is fundamentally contrastive: we test one hypothesis relative 10 another. This idea is at the heart of most of the statistical methods used by contemporary scientists. An example tends to illuminate the ideas of evidence as fit with data, fundamentally contrastive, and, ultimately, its role in testing hypotheses.

Rossi and Vassella conducted a pediatric study of headaches and tumors. ${ }^{30}$ By carefully parsing symptoms, they were able to determine that a cluster of symptoms were more telling in the identilication of tumor over migraine. One symptom in particular serves to highlight this point: nocturnal headache with vomiting was present in eleven of sixty-seven children with brain tumors and only two of 600 with of sixty-seven children waike hood: the observation of noclurnal headache wilh vomiting favors the brain tumor hypothesis over the migraine hypothesis, since the probability of the observation of nocturnal headache with vomiting given the subject has a brain tumor is much higher than the probability of the observation of nocturnal headache with vomiting given the subject has migraines. So, the observation of nocturnal headache with vomiting is evidence for brain tumors, rather than migraines. In fact, at a ratio of about 55 to 1 , this symptom is pretty telling in favor of tumors. The evidence provided by this particular symptom, while strong, does not tell us whether or not a particular patient has a tumor, rather than migraine. We can only answer this question, about our degree of certainty in the tumor hypothesis, if we know the probability a random patient has a tumor in the first place. The reason for this is evident in a fuller discussion ol Bayesianism, but for our purposes it is sufficient to note that evidence alone does not tell us which hypothesis to believe. Evidence, however, is the most basic concept in the testing of hypotheses, and we can see how that might work here. Likelihoodism, thus, uses the fit with data relation, captured by the Likelihood, and the observation in question, instead of material implication 10 describe the basic machinery for judging hypotheses.

The inference pattern Likelihoodism suggests for science is as follows:

\section{Law of Likelihood}

2. $\mathrm{O}$

3. $\operatorname{Pr}(\mathrm{O} / \mathrm{H} 1)$ 's malhematical relation to $\operatorname{Pr}(\mathrm{OlH} 2)$

4. Therefore, $\mathrm{H} 1$ or $\mathrm{H} 2$ (depending on the relation found in 3 ) is favored over the other. (We have evidence for either $\mathrm{H} 1$ or $\mathrm{H} 2$ relative to the other.)

Having described the ideas above. I then had the students read chapter 2 of Elliott Sober's Philosophy of Biology." I focused on sections 1 , 2 , and 7 , but the entire chapter is worthwhile as it spends some lime cashing out Sober's notion of testability and addresses some of the Quinean points.

One advantage of a probabilistic account, such as Bayesianism or Likelihoodism, has over Falsificationism is that it can provide the tools for demonstrating that science is not devastatingly limited (at best) by Quine-Duhem Underdetermination. Sober offers a simple, but compelling example:

I draw a card at random from a standard deck of cards without looking at it. The probability that it is the seven of hearts is $1 / 52$. You then inform me that the card is red. This information confirms the hypothesis that the card is the seven of hearts, not in the sense of insuring that the hypothesis is true, but in the sense of making the hypothesis more plausible than it was before; the probability that I have the seven of hearts has just increased to I/26. However, this infornation does not confinn that the hypothesis that the card I hold is a seven; the probability that I have a seven remains what it was, namely $1 / 133^{32}$

It is the hypothesis that the card is a heart that is doing all the confirmalory work. The chance that you have a heart, based on the observation that the card is red, doubled (from $1 / 4$ to $1 / 2$ ). So, using conditional probabilities in our scientific epistemology demonstrates a way around the Quine-Duhem challenge. This example also served to help my students get a handle on the probability math involved in Likelihood reasoning.

How then would a ghost hunter proceed, if she were a scientist? If Likelihoodism is correct, the core process would be to determine a connection between the observations that would provide evidence for the hypothesis there is a ghost, rather than some salient alternate hypothesis. In order to do this, there must be some way to fit the data to the ghost hypotheses. In the tumor example above, this is done by fitling some observation (noclurnal headache with vomiting) to known cases of tumor, and a salient contrast, migraine, and determining the frequencies. The other common means of linking observations to hypotheses is by deducing them from theory, just as in the Popperian case. For example, Mendelian Genetics tells us that the probability of observing an offspring with dry earwax from a pair of heterozygote, human parents is $0.25 .{ }^{33}$ As a result, our scientist ghost hunter would develop or seek a theory that provides probabilistic connections between ghostly observations and ghosts, or to find cases of ghosts and determine the frequency of various observations.

\section{Additional Notes}

The sections above constitute the core of my discussion of ghost hunting in relation to teaching some basic scientific epistemology. That said, I have taught Harman's "Inference to the Best Explanation," excerpts from van Fraassen's The Scientific Image, Soher's "Contrastive Empiri- 
cism," Forster and Sober's "How to Tell When Simpler, More Unified, or Less Ad Hoc Theories Will Provide More Accurate Predictions," and Mayo's "Novel Evidence and Severe Tests." I also think it would be interesting to teach Sober"s "Testability," Leonelli's "What Counts as Scientific Data? A Relational Framework." Longino's Science as Social Knowledge: Values and Objectivisy in Scientific Inquiry, excerpts from Whewell's Theory of Scientific Method, Little's "Reflective Equilibrium and Justification," and Glymour's "Explanations, Tests, Unity and Necessity," in conjunction with a ghost hunting experience. Undoubtedly there are many other options that could be connected.

It is also worth noting that none of the students in either of my classes seemed to have been taken by the 'backfire effect' suggested by Schmaltz and Lilienfeld, and spelled out in Lewandowsky et al. ${ }^{34}$ The 'backfire effect' occurs when someone comes to assign unwarranted credulity to a position when it is presented in conjunction with warranted positions. Either way, we agree with Schmaltz and Lilienfeld that it is critical to separate the good reasoning from the ghost hunting itself, and that continued framing of the good reasoning being taught is not a property of ghost hunting as it is done today (or maybe ever).

\section{Conclusion}

Ghost hunting can be a fun and worthwhile addition to any course, we have used contemporary ghost hunting as a way of teaching reasoning in three different ways, in three different classes. We taught it as a unit, an extracurricular activity linked to a class, and as class in its own right. To our minds, the benefits have been obvious-student engagement, an expanded campus profile for our work, and a novel way to help students engage with science and scientific reasoning, without advanced knowledge of any particular science. Obviously, there are a few drawbacks, but most have to do with planning for students to do something outside of the classroom and in groups. In this paper, we have provided a detailed set of notes and thoughts regarding a solid introduction of ghost hunting to any class on reasoning, including scientific reasoning.
Appendix: Koolage's Ghost Hunting Scaffolding

\section{Ghost Hunting Preparation Sheet}

Nalure of the Haunting (Quick History)

- Gather and record details regarding the haunting, ghost, or site of search

\section{Background Theory and Supplemental Research}

- Gather sources regarding the nature of ghosts, hauntings, etc.

- Research other possible attempts to hunt the ghost in question

- Interview witnesses

\section{Hypothesis Generation}

- Formulate a number of testable hypotheses combining what you know from your work regarding the Nature of the Haunting and your Background Theory and Supplemental Research

- Be sure to identify observable consequences of your hypotheses

- Consider some possibie techniques to conlirm your hypotheses in light of the observable consequences you have identified

- Note that hypotheses may best be described in terms of your best account of the nature of science. E.g., If $X$ were true, $C$ would be a matter of course, where $C$ is something surprising we observe, and $X$ is a hypothesis (Pierce's Abduction); If $\mathrm{X}$, then $\mathrm{Y}$, where $\mathrm{X}$ is your hypothesis and $\mathrm{Y}$ is an observational consequence (Popper's Falsification); or $\operatorname{Pr}(\mathrm{O} \mid \mathrm{H})$, where $\mathrm{O}$ is an observation made probable by the truth of $\mathrm{H}$, a hypothesis (The Likelihood Principle)

\section{Experimental Tools}

- Make a list of equipment you might need to gather the observations that will allow you to check your hypotheses

- Collect your required equipment well before the day of your hunt 


\section{Prepare to Record and Report}

- Prepare, in advance, a way of recording and keeping the data and evidence you gather

- Record your work above in a clear and presentable manner

- Calibrate all Experimental Tools prior to your hunt, and record the manner they were calibrated

- Organize your data and evidence upon return from your hunt

\section{Report}

- Prepare a presentation of your Ghost Hunt (5-10 minutes in length)

- Be sure to highlight your scientific reasoning in the presentation

- Be sure to present your best or most impressive evidence

\section{Notes}

Thanks 10 Danielle Clevenger for her attention to, and comments on, several versions of this paper. Also, thanks to Tracy Sontag, Cliris Forcman, Amelia Pamis, and Cliris Deacons. for their lloughts on a preliminary version of the gloust hunting unit. Also, thanks (o) Fred Harrington for feedback on an initial draft of this paper.

1. "Easten New Age Beliels Widespread: Many Americans Mix Multiple Faitlss." Pew Rescarchl Center for the People \& the Press. $20(09$.

2. Edgewood College encourages its instructors to get students more involved with the local community, as "community" is one of the institution's core values along with truth, justicc, compassion, and partnership.

3. I had one student who needed (o) be excused on llie day I showed some clips from Ghosı Adientures. She told me later that the idea of ghosis "freaked [her] out too much."

4. Karl Popper, "Science: Conjectures and Refutations"; Gilbert Harman, "The Inference to the Best Explanation”: Elliolt Sober, "Creationism," 27.

5. This is an important point. We purposely incorporated elements that make objective evidenec collection more difficult. For instance. we went athead and turned off lights making visual observation more difficult and prone to error.

6. I've been using Lewis Vaughn, The Power of Critical Thinking: Effective Reasoning abous Ordinury and Exuraordinary Claim.s.

7. I do treat inference to the best explanation as an induction. There is dispute about this, but for my classes, inductive inferences are just those that are not deductive. My position is that an inductive inference is any inference where the premises do not guarantee the truth of the conclusion.

8. It should be noted that this matcrial would find a home in standard critical thinking courses as well as philosophy of science courses. Here we will deal with inference to the best explanation as it would be found in an introductory textbook. For a more in depth look at this kind of inference, see llic section on abduction below.

9. Melissa Martin Ellis. The Everything Ghosf Humting Book: Tips, Tools, and Technigues for Eyploring the Supersatural World.

10. Patrick Grim. Philosempluy of Scichec emel the Occult.

11. Gary Hardcastle and Matthew H. Slater, "A Novel Exercise for Teaching the Philosophy of Science." This method is an interesting response to this chatlenge.

12. Sec the Appendix for the workshect.

13. Here are a couple of examples: hllp://www.easternecho.com/index.php/ article/2(H)9/10/starkweather_hall surrounded by_haunted_history and https://www. ernich.edu//tonors/documents/starkiveatherhistory.pdr.

14. Ellis, The Everyhing Ghost Hombing Book.

15. Elliott Sober, "Creationism." 27: Sober, "Evolution without Naturalism”; Kristin Andrews, "The Seience of Other Minds," 23.

16. Andrews, "The Science of Ollier Mlinds," 31.

17. Ibid.. 44.

18. Soher, "Evolution ivithout Naturalism," 187.

19. Sober, "Creationism." 27.

20. An anonymous reviewer provides a serious concem regarding this section's discussion, which I hag here for llic reader. This section outlines the malterial that I did pursue with his students, hut is far from an even ltanded diseussion of Nalturilism. Mly intention was 10 be as charitable as possible to the idea that ghost hunting could be a science. That said, see, for examuple. Martin Malıner, "The Role of Melapliysical Naturalism in Science," for a dissenting view to the one I offer here.

21. Antony Flew "Parapsyclolology: Science or Pscudoscience?," 214.

22. Alfred Wegener. The: Origin of Continents and Oceans.

23. Larry Latudan. "A Confutation of Convergent Realism."

24. Iloid.

25. Harry Frankfurt, "Pcirce's Notion of Abduction."

26. Ellis, The Eventhing Ghost Huming Book.

27. Popper, "Science."

28. Thanks to an anonymous reviewer for pointing out llis line of exploration. Interested readers may wisls to start with Maarten Boudry and Johan Bracckman's "Immunizing Strategies and Epistemic Defense Mechanisms."

29. Jan Hacking. Logic of Statistical Inference.

30. Livia Rossi and Franco Vassella, "lleadache in Children will Brain Tumors."

31. Sober, "Creationism."

32. Ibid. 246. 
33. This matli is for a trait determined at a single gene locus with only two alleles that follow Menelel's Law of Dominance. A more familiar example would be blue cyes. but it turns out that cye color is not a single allele trait.

34. Rodney Schmatly, and Scott Lilienfeld. "Hauntings, Homeopathy, and the Hopkinsville Goblins: Using Pscudoscience to Teach Scientific Thinking": Stephan Lewndowsky ct al.. "Misinfonnation and lts Correction Continued Influence and Successful Debiasing."

\section{Bibliography}

Andrews, Kristin. "The Science of Other Minds," in The Animel Mind. Routledge, 2015. Boudry, Maasten, and Johan Bracckman. "Immunizing Strategies and Epistemic Defense Mechanisms." Philosophria 39(1) (2011): 145-61. litips://doi.org/10.1007/s11406-(010-9254-9

Ellis, Melissa Martin. The Evernthing Ghost lfunting Book: Tïps. Tools, and Techusiques for Eaxploring the Supermesural World. New York: Adams Media, 2014.

Flew. Antony. "Parapsychology: Science or Pscudoscience?", in Plsilosophy of Science and the Occuls, ed. Patrick Grim, 214-31. Albany: State University of New York Press, 1982.

Forster, Malcolm, and Elliott Sober, "How to Tell when Simpler. More Unified, or Less ad hoc Theorics Will Provide More Accurate Predictions." The British Joumal for the Philosophy of Science 45(1) (1994): I-35. hetps://doi.org/l().1093/bjps/45.1.1

Frankfurt, Harry. "Peirce's Notion of Abduction." The Journal of Philosopplyy 55(14) (1958): 593-97. hups://doi.org//0.23(07/2021966

Glymour, Clark. "Explanations, Tests, Unity and Necessity." Nous.s (1980): 31-50 https://doi.org/l(1).2307/2214888

Grim. Patrick. Plsilessophly of Scicnce emel the Occult. Albany: SUNY Press, 1982.

Hacking, Ian. Logic ofStatissical Inference. Cambridge: Cambridge University Press, 1965. hups://doi.org/10.1(017/CBO9781316534960)

Hardcastle, Gary, and Mattliew Slater. "A Novel Exercise for Teaching the Philosophy of Science." Plilosophy of Scicnce 81(5) (2014): 1184-96. hilps://doi.org/10.1086/678240

Harman, Gilber, "The Inference in the Best Explanation." Philosophly Review 74 (1965): 88 95. hitps://doi.org/10.23(07/2183532

Laudan, Larry. "A Confutation of Convergent Realism." Philosophy of Science 48(1) (1981): 19-49. https://doi.org/10.1086/288975

Leonelli. Sabinal. "What Counts as Scientific Datti? A Relational Framework." I/hilosophy of Science 82(5) (2015): 81()-21. h11ps://doi.org/10.1086/684083

Lewandowsky. Stephan, Ullrich Ecker. Colleen Seifer, Norbert Schwarz, and John Cook. "Misinformation and Its Correction: Continued Influence and Successful Debiasing." Psychological Science in the Public luserest 13(3) (2012): 106-31. https://doi.org/10.1177/1529100612451018

Little, Danicl. "Reflective Equilibrium and Justification." The Soushern Journal of Pltilo.sop)lyy 22(3) (1984): 373-87. https://doi.org/10.1111/j.2041-6962.1984.1b0)(0354.x

Longino, Helen E. Scicnce as Social Kunwledge: Values and Objectivity in Scientific Imepriry. Princeton, N.J.: Princeton University Press. 1990).

Mahner, Martin. "The Role of Metaphysical Naturalism in Science." Science \& Education 21(10) (2012): 14.37-59, ht1ps://doi.org/10.1007/s 11191-011-9421-9)
Mayo. Dehorah. "Novel Evidence and Severe Tests." Plislossophyo of Scicince 58(4) (1991) 523 52. hitps://doi.org/10.1086/289639

Pew Rescarcll Center for tlue People \& the Press. "Eastern New Age Belicfs Widespread: Many Americans Mix Multiple Faiths." 2009.

Popper. Karl. "Science: Conjectures and Refutations." in Philosophts of Science and the Occill, ed. Patrick Grim. 104-10. Alhiny: SUNY Press, 1990.

Rossi. Livia, and Franco Vassella, "Headache in Children with Brain Tumors." Child's Nerious Sysirem 5(5) (1989): 307-09. hitps://doi.org/10.10)07/BF00274519

Schmaltz, Rodney, and Scott O. Lilienfeld. "Illauntings, llomeopathy, and the Hopkinsville Goblins: Using Pscudoseience 10 Teach Scientific Thinking," in Pedagogical Psichology: Be'yomel the 2/st Cenmury, ed. Gretchen M. Recvy and Stanley N. Bursten. Lausanne: Fronticrs Media, $2(015$.

Sober. Elliott. "Contrastive Empiricism." Scicurific Theories 14 (1990): 392-412.

Sober. Elliott. "Creationism," in Philossophy of Biology. Boulder, Colo.: Westvicu Press, 2000.

Sober. Elliott. "Evolution without Naturalism." Oxford Studiess in IPlsilosophy of Religions $3(2011): 187-221$.

Sober, Elliott. "Testability." Pmecedings and Addresses of Ihe American Philesophical Association 73(2) (1999): 47-76. hitps://doi.org/10.23(07/31.31087

Van Fraissen, Bals. The Sciemafic Image. Oxford: Oxford Uniyersity Press, 1980. hitps://doi.org/10.1093/(0198244274.001.0001

Vaughis. Lewis. The Power of Critical Thinking: Efdective Re'aseming about Oralinan and Extratedinary Claims. Oxforel: Oxford University Press. 2015.

Wegener. Alfred. The Origin of Comrinents and Oceans. North Chelmsford. Mass.: Courie Corporation, 1966.

Whewell. William, and Robert Butts. Theony of Scienific Method. Hackeit Publishing. 1968 .

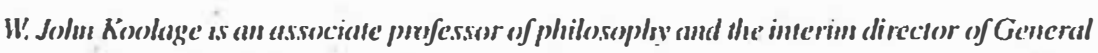
Ealucation at Easternt Michigen Universitn: His research focuses on the application of ideas from general philosophy of science on other pressing and current ansestions. inclueding climate change and gan control. He is also tern interested in the studt of teaching and learning. E-mail: whoolage@ @ mich.e'du.

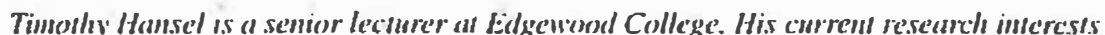
imbolve issues that reside at the intersection of episfemologg: philosophly of science, ceth-

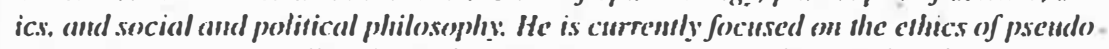
scientific and sciemtifically delnumked medical treamments. E-mail: thansel@edgewood.edn. 